\title{
Strategi Promosi Penyanyi Cover di Media Sosial Instagram
}

\author{
Mulyani Citra Setiawati, Farid Rusdi \\ mulyanicitras@gmail.com,farid@fikom.untar.ac.id \\ Fakultas Ilmu Komunikasi Universitas Tarumanagara
}

\begin{abstract}
Many cover singers use social media to promote the results of their creativity on Instagram and sometimes they immediately get a positive response from their followers. A cover singer is a singer who sings someone's original song. The purpose of this study was to determine the promotional strategies adopted by cover singers on Instagram social media and the strengths and weaknesses of Instagram social media in the promotion process. The theoretical foundation used in this study include promotional strategies and social media. The research method used in this study is a qualitative method with a case study approach. The speakers in this study are three cover singers who use social media Instagram as a means to promote and provide information to their followers and a social media expert resource. The results of this study indicate that the promotional strategy adopted on social media for these three cover singers is to utilize free and paid features found on Instagram that are packaged differently. This difference is seen when they compare themselves. The promotional mix strategy used is a push strategy by introducing a cover singer profile then determining the features to be used and an attractive strategy for a cover singer directing to marketing activities aimed at such as using swipe up features that can switch to YouTube. One of Instagram's strengths is being able to include a number of features like swipe up that are easy to use. This is what makes people want to do promotions on Instagram.
\end{abstract}

Keywords : instagram and cover singers, promotion, social media.

\begin{abstract}
Abstrak
Banyak penyanyi cover yang menggunakan media sosial untuk mempromosikan hasil kreativitasnya di Instagram dan terkadang mereka langsung mendapatkan respon positif dari pengikutnya. Penyanyi cover ialah penyanyi yang menyanyikan ulang lagu original seseorang. Tujuan penelitian ini adalah untuk mengetahui strategi promosi yang diterapkan oleh penyanyi cover di media sosial Instagram dan kekuatan serta kelemahan pada media sosial Instagram dalam melakukan proses promosi. Landasan teoritik yang digunakan dalam penelitian ini diantaranya ialah strategi promosi dan media sosial. Metode penelitian yang digunakan dalam penelitian ini adalah metode kualitatif dengan pendekatan studi kasus. Narasumber dalam penelitian ini ialah tiga orang penyanyi cover yang menggunakan media sosial Instagram sebagai sarana untuk melakukan promosi dan memberikan informasi kepada pengikutnya dan seorang narasumber ahli media sosial. Hasil penelitian ini menunjukan bahwa strategi promosi yang diterapkan di media sosial ketiga penyanyi cover ini ialah memanfaatkan fitur-fitur gratis dan berbayar yang terdapat di Instagram yang dikemas secara berbeda. Perbedaan ini terlihat saat mereka mem-branding dirinya masingmasing. Strategi bauran promosi yang digunakan adalah strategi mendorong dengan cara memperkenalkan profile penyanyi cover kemudian menentukan fitur yang akan digunakan dan strategi menarik penyanyi cover mengarahkan ke kegiatan pemasaran yang ditujukan seperti penggunaan fitur swipe up yang dapat beralih ke YouTube. Salah satu kelebihan Instagram adalah mampu mencakup sejumlah fitur seperti swipe up yang mudah digunakan. Hal inilah yang membuat orang ingin melakukan promosi di Instagram.
\end{abstract}

Kata Kunci : instagram dan penyanyi cover, media sosial, promosi. 


\section{Pendahuluan}

Perkembangan internet sudah dapat dirasakan secara signifikan oleh masyarakat. Kehdiraannya memudahkan masyarakat dalam mengakses berita, mengakses informasi, mencari hiburan ataupun menjadi pelaku penyebaran informasi terhadap sesama pengguna melalui media baru yang disebut Internet.

Berdasarkan hasil survei Asosiasi Penyelenggara Jasa Internet Indonesia (APJII), jumlah pengguna internet di tahun 2018 mengalami peningkatan dari tahun sebelumnya tercatat dari total populasi sebanyak 264,16 juta jiwa penduduk Indonesia, ada sebanyak 171,17 juta jiwa atau setara dengan 64,8 persen yang sudah terhubung ke internet.

Romli dalam Azeharie (2015) menjelaskan bahwa para pengguna menggunakan media sosial untuk menyebarkan informasi dan membuat pesan ke dalam dunia maya ataupun jejaring sosial, dengan adanya hal ini Romli mengajak semua pengguna media sosial untuk ikut memberikan umpan balik dan kontribusi dengan penyebaran yang sangat cepat. Dalam hasil riset We Are Social Hootsuite yang dirilis Januari 2019 pengguna media sosial di Indonesia sudah mencapai 150 juta atau setara dengan 56 persen dari total populasi. Jumlah ini naik sebesar 20 persen dari survei sebelumnya. Sementara pengguna media sosial di gadget (mobile) mencapai 130 juta atau setara dengan 48 persen dari populasi.

Pemasaran produk pada zaman dahulu dan zaman sekarang sangatlah berbeda. Zaman sekarang setiap orang bisa menggunakan teknologi yang canggih agar bisa menghemat biaya pengeluaran, salah satunya yaitu dengan menggunakan media sosial. Menurut Van Dijk (2013) media sosial merupakan wadah yang memberikan fokus kepada penggunanya serta memberikan fasilitas untuk melakukan kolaborasi dan aktivitas, hal ini bertujuan untuk membangun dan menguatkan hubungan antar penggunanya. Saat ini banyak sekali content creator atau influencer yang mendapatkan keuntungan penghasilan dari produk dan jasa yang dipromosikan salah satunya penyanyi cover. Penyanyi cover merupakan kumpulan dari penyanyi solo atau kelompok yang menyanyikan kembali lagu-lagu terbaik dengan aransemen musik yang berbeda. Menurut Kinnear dan Kenneth dalam Setiyaningrum, et all., (2015) promosi ialah proses pertukaran informasi antara penjual dan pembeli yang bersifat membujuk ini merupakan cara kerja dari komunikasi pemasaran.

Penyanyi cover menggunakan media sosial Instagram sebagai sarana melakukan promosi. Saat ini Instagram memang sangat digandrungi oleh semua kalangan mulai dari anak-anak sampai orang tua. Menurut Bambang dalam Sidiq, Anwar (2017) Instagram merupakan aplikasi yang menampilkan dan membagikan foto serta video yang dapat dilihat oleh para pengikutnya dan mereka bisa memberikan tanggapan seperti komentar ataupun yang lainnya. Penyanyi cover memilih media sosial Instagram untuk melakukan promosi. Data dari liputan6.com Indonesia merupakan negara pengguna Instagram terbesar urutan ke-empat dengan jumlah pengguna sebesar 56 juta dengan rentang usia terbanyak 18 sampai 24 tahun yang menggunakan Instagram. Data yang dirilis oleh We Are Social juga mengatakan hal yang sama dengan liputan6.com bahwa pengguna media sosial Instagram di Indonesia menduduki peringkat ke-empat, yaitu sebesar 80 persen masyarakat di Indonesia sangat aktif menggunakan Instagram. 


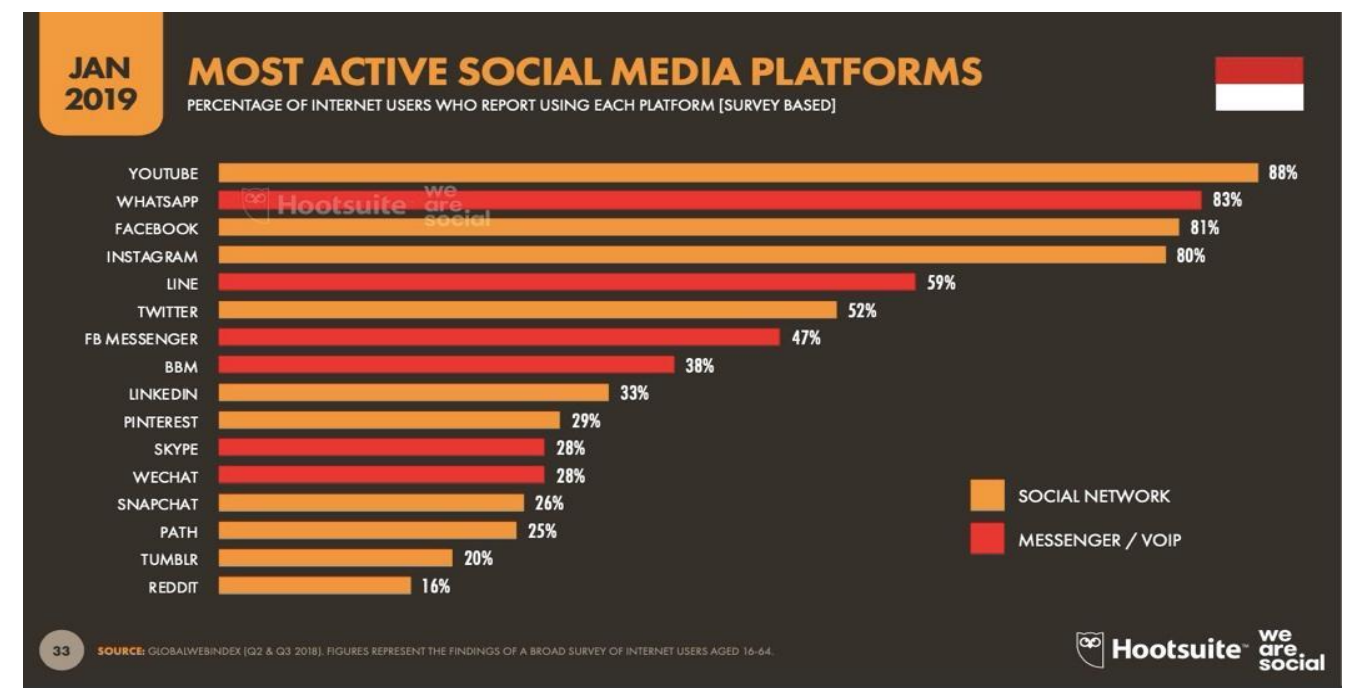

\section{Gambar 1 Jumlah Pengguna Media Sosial yang Aktif di Indonesia}

Sumber: We Ara Social Hootsuite Indonesian Digital Report 2019

Dengan media sosial Instagram, kini penyanyi cover dapat mempromosikan hasil kreativitasnya dengan cara membagikan cuplikan tampilan video yang telah dibuat lalu menambahkan link versi full video yang ditujukan langsung ke laman YouTube dengan menggunakan fitur "swipe up" dari instastories. Pada feeds Instagram penyanyi cover melakukan upload teaser video dengan menggunakan caption yang menarik dan menaruh link video YouTube agar mudah untuk di akses. Masih terdapat banyak fitur-fitur Instagram untuk melakukan promosi ataupun interaksi seperti question box, polling, add to post your story, dan lain-lainnya. Penelitian ini dilakukan untuk mengetahui bagaimanakah strategi promosi yang diterapkan oleh penyanyi cover di media sosial Instagram dan untuk mengetahui bagaimanakah kekuatan serta kelemahan pada media sosial Instagram dalam melakukan proses promosi?

\section{Metode Penelitian}

Penelitian yang dilakukan oleh penulis adalah untuk mengetahui strategi promosi yang diterapkan oleh penyanyi cover di media sosial Instagram dan untuk mengetahui kekuatan serta kelemahan pada media sosial Instagram dalam melakukan proses promosi. Metode penelitian yang digunakan dalam penelitian ini adalah metode penelitian kualitatif dengan pendekatan studi kasus - deskriptif. Menurut David Williams dalam Moleong, Lexy J. (2018) metode penelitian kualitatif adalah metode yang digunakan untuk meneliti dan menganalisa permasalahan yang diteliti secara alamiah untuk memberikan gambarannya. Menurut Yin (2014) pengertian studi kasus adalah proses pencarian pengetahuan empiris guna menganalisa dan meneliti berbagai fenomena dalam konteks kehidupan nyata. Pendekatan studi kasus ini dapat diterapkan saat batas antara fenomena dan konteks masih belum terlihat dengan jelas serta ada berbagai sumber yang dapat dijadikan acuan bukti dan penggalian informasi secara lebih dalam. Nazir, Moh (2011) menjelaskan metode deskriptif ialah proses mencari fakta dengan pandangan yang akurat. 
Penulis mengambil subjek penelitian dengan tiga orang penyanyi cover yang memulai kariernya pertama kali lewat Instagram dan satu orang ahli media sosial, yaitu:

1) Rama Davis sebagai penyanyi cover yang menggunakan media sosial Instagram dari tahun 2015.

2) Raynaldo Wijaya sebagai penyanyi cover yang menggunakan media sosial Instagram dari tahun 2013.

3) Alya Nur Zurayya sebagai penyanyi cover yang menggunakan media sosial Instagram dari tahun 2016.

4) Abang Edwin Syarif Agustin sebagai ahli media sosial yang telah bekerja selama 19 tahun dan saat ini telah mendirikan Bangwin Consulting.

Penulis menggunakan beberapa cara untuk melakukan pengumpulan data, yaitu: studi pustaka, menurut Sugiyono (2016) studi pustaka ialah kegiatan pengumpulan data menggunakan buku, artikel, jurnal ataupun penelitian terdahulu sebagai referensi dan kajian teoritis dari ilmu-ilmu yang diteliti. Esterberg dalam Sugiyono (2016) wawancara adalah proses tanya jawab untuk mendapatkan pertukaran informasi yang dilakukan antara dua orang atau lebih. Menurut Nasution yang dikutip dalam buku Metode Penelitian Kualitatif, Kuantitatif dan R\&D observasi ialah pengamatan yang dilakukan untuk mengumpulkan data dan fakta mengenai pengetahuan di dunia nyata. Dokumen merupakan kumpulan kejadian yang sudah lewat, biasanya kejadian ini dikumpulkan dalam bentuk karya lain, gambar, atau tulisan.

\section{Hasil Temuan dan Diskusi}

Pada penelitian ini penulis lebih memfokuskan pembahasan pada strategi promosi yang diterapkan oleh penyanyi cover di media sosial Instagram dan untuk mengetahui tentang kekuatan kelemahan pada media sosial Instagram dalam melakukan proses promosi. Berdasarkan hasil temuan dalam penelitian ini, penulis menemukan bahwa pemanfaatan media sosial saat ini semakin luas dan bisa membawa pengaruh positif maupun negatif bagi penggunanya. Beberapa tahun belakangan, banyak sekali penyanyi cover yang menggunakan media sosial untuk mempromosikan hasil kreativitasnya karena mereka menganggap media sosial sebagai wadah yang sangat efektif dan efisien. Hasil kreativitas yang dimaksud dapat berupa lagu original yang dinyanyikan kembali dengan menggunakan video musik yang dibuat oleh mereka sendiri atau hasil karya original dari mereka dikarenakan sekarang ini beberapa penyanyi cover sudah memiliki karya original sendiri. Menurut Kinnear dan Kenneth dalam Setiyaningrum, et all., (2015) promosi ialah proses pertukaran informasi antara penjual dan pembeli yang bersifat membujuk ini merupakan cara kerja dari komunikasi pemasaran.

Tidak dapat dipungkiri lagi hampir seluruh masyarakat di Indonesia mengetahui dan aktif menggunakan media sosial. Setelah penyanyi cover tidak menggunakan media sosial SoundCloud sebagai sarana promosi, mereka beralih ke media sosial lain yaitu Instagram. Alasan penyanyi cover memilih media sosial Instagram untuk melakukan promosi karena Instagram termasuk ke dalam layanan media sharing dengan fokus utama untuk membagikan konten foto atau video. Instagram hampir digunakan oleh semua kalangan, tetapi mereka lebih memfokuskan kepada milenial dengan segmentasi usia 18 sampai 25 tahun karena di usia tersebut 
mereka aktif menggunakan media sosial. Instagram sendiri juga mudah terhubung ke media sosial lain sehingga sangat memudahkan mereka dalam melakukan promosi. Selain itu di Indonesia, Instagram termasuk sebagai media sosial yang paling aktif urutan ke-empat. Melakukan promosi di Instagram tidak mengeluarkan biaya sama sekali kecuali bagi mereka yang ingin menggunakan fitur promotion ads, pengeluaran biaya untuk promotion ads sendiri dapat diatur sesuai dengan keuangan yang dimiliki. Banyak fitur-fitur gratis di Instagram yang dapat dimanfaatkan oleh penyanyi cover untuk melakukan promosinya seperti, penggunaan fitur swipe up, fitur interaktif question box, atau fitur polling (vote) sehingga banyak penyanyi cover yang tertarik untuk menggunakan media sosial sebagai sarana promosi.

Strategi promosi yang diterapkan oleh penyanyi cover benar-benar diperhatikan biasanya dalam satu hari mereka hanya mem - posting beberapa foto atau video saja, tetapi jika bahan posting-an yang mereka miliki cukup banyak mereka menjadwalkan posting-an tersebut untuk di-upload sesuai dengan jam yang ditentukan. Jika bahan posting-an hanya sedikit biasanya mereka akan upload selama 2 jam sekali. Hal ini dilakukan agar feeds mereka tidak terlihat spam (kacau). Berbeda halnya dengan instastories mereka tidak memiliki aturan khusus karena dalam waktu 24 jam posting-an tersebut akan hilang dengan sendirinya.

Menurut Rama Davis, saat melakukan promosi banyak orang yang tidak memperhatikan cara berpromosi yang baik dan benar. Terkadang orang suka mengunggah foto di laman feeds sangat banyak sekali, padahal hal demikian membuat orang untuk malas melihat foto-foto tersebut. Rama memiliki strategi promosi yang baik dan benar. Hal ini telah diungkapkannya:

"Strategi promosi yang aku terapkan, dalam satu hari aku hanya ingin posting di feeds satu sampai dua kali saja dengan jarak waktu yang berbeda, hal ini dikarenakan agar tidak terjadi spam, dan orang jadi tidak bosan melihat feeds aku. Untuk instastories tidak ada aturan khusus bisa sebanyak-banyaknya upload karena akan hilang dengan sendirinya dalam jangka waktu 24 jam. Kadang aku juga menggunakan fitur-fitur gratis yang telah tersedia, tapi paling sering pakai swipe up karena sudah terhubung ke semua aplikasi”.

Raynaldo menjelaskan banyak cara yang dilakukan oleh penyanyi cover untuk melakukan promosi. Ia melakukan promosi hanya untuk pengguna yang telah mengikutinya di Instagram sejak awal berkarier dan ia tidak memiliki cara promosi yang khusus.

"Aku tidak menggunakan strategi promosi yang khusus. Aku melakukan promosi hanya untuk para followers aku saja, mungkin dengan cara masuk ke explore. Untuk promosi hasil cover-an biasanya aku upload 2x seminggu dan fitur yang paling sering digunakan fitur add post to your story dan swipe up. Hanya itu saja”.

Disisi lain, Alya mengatakan ia jarang sekali melakukan promosi untuk karya cover-an ia lebih gencar untuk mempromosikan karya originalnya. Ia pun pernah menggunakan fitur promotion ads dengan biaya yang minim untuk menunjang proses promosi ini.

"Untuk karya cover aku jarang mempromosikannya. Biasanya aku menerapkan strategi promosi hanya untuk karya original aku sendiri dengan cara memanfaat semua fitur gratis yang telah tersedia di Instagram, terkadang aku melakukan promosinya juga seperti bercerita kepada followers aku. 
Untuk single yang Ruang Tanpa Rencana aku menggunakan promotion ads dengan budget yang minim sekali”.

Hasil penelitian yang telah diuraikan diatas dapat disimpulkan bahwa strategi promosi yang diterapkan oleh penyanyi cover rata-rata memiliki kesamaan dengan menggunakan fitur-fitur gratis di Instagram dan instastories, tetapi ada perbedaan pada saat mereka mem-branding dirinya masing-masing. Namun, ada penyanyi cover yang menggunakan fitur promosi tambahan seperti Alya Zurraya yang menggunakan promotion ads sebagai sarana promosinya. Promotion ads hampir sama dengan kegiatan di Instagram stories bedanya promotion ads merupakan cara beriklan melalui konten berbayar untuk dapat menjangkau target audiens secara lebih luas. Untuk merancang bauran promosi di media sosial penyanyi cover dapat menggunakan dua strategi yaitu strategi mendorong (push) dan strategi menarik (pull). Strategi mendorong yang dilakukan oleh penyanyi cover yaitu dengan cara memperkenalkan profile masing-masing penyanyi cover di Instagram kemudian mereka melakukan promosi menggunakan fitur-fitur yang telah mereka tentukan misalnya penggunaan fitur swipe up, sedangkan untuk strategi menariknya penyanyi cover melalui instagramnya mengarahkan audiens ke kegiatan promosi yang ditujukan pada media sosial lainnya, misalnya dari penggunaan fitur swipe up di Instagram mengarahkan followers ke media sosial lainnya seperti YouTube, ke aplikasi Spotify, dll. Strategi seperti ini sangat diperlukan untuk menggiring pengikutnya.

Dalam melakukan promosi di media sosial, tentunya akan ada aspek-aspek yang sangat penting untuk diperhatikan oleh penyanyi cover seperti kekuatan dan kelemahan dari media sosial Instagram sebagai sarana promosi. Dari sisi kelemahan penyanyi cover mengatakan algoritma Instagram cukup berbeda, hal ini dikarenakan sekarang kalau mem-posting sesuatu sesuai dengan urutan jam, hasil posting-an tersebut akan berada diatas sesuai dengan jamnya tetapi sekarang dinilai dari berapa banyak orang yang menyukai posting-an, jadi semakin banyak yang menyukainya akan semakin naik algoritma berinteraksi dengan followers. Namun, orang sangat berbeda tidak semua orang aktif untuk membalas komentar ataupun hal lainnya sehingga mereka merasakan kekacauan. Kemudian, terjadinya persaingan yang semakin ketat, karena banyak penyanyi cover yang mulai bermunculan tapi mereka melihat dari sisi peluang yang ada. Terkadang juga masih ada feedback negatif dari pengikut dan kelemahan secara umum masih terasa yaitu penyebaran konten-konten negatif seperti hoax.

Dari sisi kekuatan, Instagram termasuk media sosial yang sangat kuat karena hampir semua fitur terdapat di Instagram, yang ada diaplikasi lain diambil oleh Instagram terus lebih dikembangkan. Instagram juga lebih improvisasi semua pengguna bisa membuat filter untuk menarik perhatian pengguna. Hampir semua orang juga menggunakan media sosial untuk menyebarkan informasi yang luas kepada orang lain dan dapat digunakan sebagai ajang promosi, karena selama ini penyanyi cover melakukan promosi di Instagram dan mendapatkan respon yang positif.

\section{Simpulan}

Berdasarkan hasil temuan dan analisis, penulis dapat menyimpulkan bahwa strategi promosi yang diterapkan oleh penyanyi cover memanfaatkan fitur-fitur gratis 
maupun berbayar yang tersedia di Instagram. Strategi yang diterapkan penyanyi cover untuk melakukan promosi ialah dalam sehari mem-posting foto atau video di laman feeds tidak boleh terlalu banyak agar tidak terlihat spam (kacau) dan mereka memberikan jeda waktu dalam melakukan posting-an. Jika mereka memiliki bahan posting-an cukup banyak mereka akan upload dalam waktu dua jam sekali dan jika mereka memiliki bahan posting-an sedikit mereka akan upload dengan jeda waktu paling lama lima jam sekali, hal ini dilakukan agar followers mereka tidak bosan melihat hasil posting-annya. Berbeda halnya dengan posting-an di instastories mereka tidak memiliki aturan khusus karena posting-an tersebut akan hilang dengan sendirinya dalam waktu 24 jam.

Walaupun cara promosi mereka hampir sama, tetapi mereka memiliki perbedaan dalam mem-branding dirinya masing-masing. Hal ini terlihat saat mereka mempromosikan lagu original-nya. Cara seperti ini bisa disebut sebagai strategi bauran promosi yang terdiri dari strategi dorong dan strategi tarik. Strategi mendorong yang dilakukan oleh penyanyi cover yaitu dengan cara memperkenalkan profile masing-masing penyanyi cover di Instagram kemudian mereka melakukan promosi menggunakan fitur-fitur yang telah mereka tentukan misalnya penggunaan fitur swipe up. Sedangkan untuk strategi tarik, penyanyi cover melalui instagramnya mengarahkan audiens ke kegiatan promosi yang ditujukan pada media sosial lainnya, misalnya dari penggunaan fitur swipe up di Instagram mengarahkan followers ke media sosial lainnya, seperti YouTube. Strategi seperti ini sangat diperlukan agar dapat menggiring pengikutnya untuk beralih ke media sosial seperti dari Instagram ke aplikasi Joox atau Spotify.

Sebagai pengguna yang melakukan promosi di Instagram mereka juga harus mengetahui kekuatan dan kelemahan di media sosial ini. Kekuatan yang dimiliki oleh Instagram, ia hanya satu aplikasi media sosial tetapi menguasai keseluruhan fitur karena pihak Instagram selalu memberikan inovasi. Hal ini menjadi suatu pendukung bagi pengguna yang melakukan promosi. Kelemahan yang terasa karena Instagram menghilangkan jumlah likes proses bekerja algoritma Instagram menjadi aneh dan sulit ditebak, terkadang Instagram masih mengandung konten-konten yang negatif seperti hoax.

\section{Ucapan Terima Kasih}

Penulis mengucapkan terima kasih kepada pihak Fakultas Ilmu Komunikasi Universitas Tarumanagara. Kemudian, kepada ketiga narasumber Rama Davis, Raynaldo Wijaya, Alya Nur Zurayya serta satu narasumber ahli 'Abang' Edwin Syarif Agustin yang telah memberikan kesempatan dan memberikan informasi kepada penulis terkait dengan penelitian yang ingin dianalisis oleh penulis. Kepada orang tua, kakak, saudara, sahabat dan teman penulis yang selalu memberikan dukungan dan mendengarkan keluh kesah yang di alami oleh penulis selama menjalankan proses penelitian ini. 


\section{Daftar Pustaka}

Azeharie, S., \& Sari, W. (2015). Penyingkapan Diri Ibas Yudhoyono Dalam Instagram Dan Reaksi Ani Yudhoyono Terhadap Postingan Ibas. Jurnal Komunikasi, 7(1). 108-117.

Moleong, Lexy J. (2017). Metodologi Penelitian Kualitatif. Bandung: PT Remaja Rosdakarya.

Nazir, Moh. (2011). Metode Penelitian. Bogor: Ghalia Indonesia.

Setiyaningrum, Ari dan Udaya, Jusuf. Efendi. (2015). Prinsip-Prinsip Pemasaran. Yogyakarta: Andi.

Sidiq, Anwar. (2017, November 16). Pemanfaatan Instagram Sebagai Media Dakwah (Study Akun @fuadbakh). Repository. September 11, 2019. Terarsip di http://repository.radenintan.ac.id/2201/

Sugiyono. (2016). Metode Penelitian: Kuantitatif, Kualitatif dan R\&D. Bandung: Alfabeta.

We Are Social. (2019, Februari 8). Berapa Pengguna Media Sosial Indonesia? Agustus 18, 2019. DATABOKS.CO.ID STATISTICS \& DATA PORTAL. https://databoks.katadata.co.id/datapublish/2019/02/08/berapa-penggunamedia-sosial-indonesia

Yin, Robert K. (2014). Studi Kasus Desain \& Metode. Edisi ketigabelas. Jakarta: Rajawali Pers. 